\title{
Küçük Renal Kitlelere Yaklaşım
}

\author{
Mustafa Sofikerim ${ }^{1}$, Mehmat Caniklioğlu² Fikret Halis $^{3}$
}

${ }^{1}$ Acıbadem Üniversitesi, Tıp Fakültesi, Üroloji Anabilim Dalı, İstanbul

${ }^{2}$ Sağlık Bakanlığı Sinop Atatürk Devlet Hastanesi, Üroloji Kliniği, Sinop

${ }^{3}$ Sakarya Üniversitesi, Tıp Fakültesi, Üroloji Anabilim Dalı, Sakarya

\section{Giriș}

$\mathrm{B}$ öbrek kitlelerinin insidansı rutin tıbbi kontroller ve üriner sistem ile ilişkisiz tıbbi değerlendirmeler sonucu son yıllarda giderek artmaktadır. Küçük böbrek kitleleri (KBK), bilgisayarlı tomografi (BT) veya manyetik rezonans görüntüleme (MR) ile tespit edilen ve genellikle renal hücreli karsinom (RHK) olmasından şüphelenilen, $4 \mathrm{~cm}$ ya da daha küçük solid kitleler olarak tanımlanır (1). Böbrek kitleleri ve KBK'lar hakkındaki bilgilerimiz her geçen gün artmaktadır. $\mathrm{Bu}$ yazıda bir klinik rehber oluşturmaktan ziyade son bir yıldaki gelişmeler ve değişimler özetlenmiştir.

\section{Etyoloji- Sınıflama- Patoloji}

Genel olarak böbrek kitlelerinin etiyolojisinde son yıllarda aydınlatılmış yeni bir gelişme bulunmamaktadır. Sigara içiciliği RHK için kesin faktör olarak bildirilmekle beraber özellikle visseral obezite, T1a evresindeki hastalarda daha yüksek Fuhrman derecesi ile ilişkili bulunmuştur $(2,3)$.

2010 TNM sinıflaması, hasta değerlendirmesinde ve bilimsel kullanım için önerilen bir sistemdir $(4,5)$. TNM sınıflaması bazı evreler için geliştirilmeye ihtiyaç duymaktadır (2). Bu sınıflamada, KBK'ların tanımlamasında eşik değer kabul edilen $4 \mathrm{~cm}$ sınırının, nefron koruyucu cerrahiye uygun olup olmadığ ${ }_{1}$ halen tartışmalıdır $(2,6,7,8)$.

Renal tümörlerin histopatolojisinde Dünya Sağlık Örgütü'nün 2004'te yaptığı sınıflama geçerliliğini korumaya devam etmektedir (2). Buna göre RHK, tüm olguların \%90'ını oluşturmaktadır. RHK olgularının ise \%80-90'1nı berrak hücreli karsinom, \%10-15'ini papiller RHK ve \%4-5'ini de kromofob RHK oluşturmakta ve bu üçlüye "major RHK alt tipleri" denmektedir. Berrak hücreli karsinomun Von Hippel Lindau geni ile ilişkisi gösterilmiştir. Papiller alt tip bazı trizomiler ile, kromofob RHK ise bazı kromozom eksiklikleri ile ilişkilendirilmiştir.

\section{Tanı}

Son yıllarda olguların büyük bir kısmı insidental olarak tanı almaktadır. Klasik triad olan yan ağrısı, makroskobik hematüri ve ele gelen abdominal kitle çok nadir görülmekte ve agresif klinik seyirin göstergesi olarak kabul edilmektedir (2).

\section{Görüntüleme}

Tanı, temel olarak abdominal görüntülemeye dayanır. Böbrek ultrasonografisi (US), kontrastlı BT ve MR, küçük ve düşük evrede bulunan KBK'ların artmış insidansından birincil derecede sorumludurlar $(1,9,10,11)$. Ancak Jamis-Dow ve ark.'ları $1 \mathrm{~cm}$ 'nin altındaki KBK'nin tanısında BT ve US'nin yetersiz kalabildiğini belirtmişlerdir (12).

Solid kitleler açısından kontrast tutan bir büyümenin saptanması malignite lehine kanıta dayalı bir bilgidir. Kistik lezyonlar açısından ise Bosniak sınıflaması geçerlidir (2). Yeni bir çalışmada, böbrek anjiomyolipomlarının BT'de görülen dondurma külahı benzeri üçgenimsi görüntüleri ile diğer lezyonlardan ayırt edilebileceği belirtilmiştir (13). BT ve MR'ın onkositom ve yağsız anjiomyolipomları malign lezyonlardan ayırt etmede yetersiz kaldığı bilinmektedir (2). Meng ve ark. ları'nın yaptığı yeni bir çalışmaya göre dinamik kontrastlı MR, RHK'lerde berrak hücreli olanlar ve olmayanlar arasında yüksek duyarlılık ve özgüllükle ayırt edicilik sağlamıştır (14). Pierorazio ve ark.'ları ise; farklı histolojik yapıya sahip KBK'ların 4 fazlı BT altında farklı ayırt edici kontrastlanma kalıpları gösterdiğini bildirmişlerdir (15). Diğer taraftan, Bird ve ark.'ları 4 fazlı bilgisayarlı tomografinin arteryel fazdaki fazladan kontrast tutulumu sayesinde onkositomları RHK'lerden ayırdetmede başarılı olduğunu belirtmişlerdir (16). Kontrast maddeler ile ilgili gelişmeler az sayıda olmakla beraber, Payton ve ark.'ları radyolojinin değişik alanlarında kullanılan bir kontrast ajan olan indosiyanin yeşili'nin renal kitleler için malignitenin belirlenmesinde yeterli olmadığını bildirmiştir (17). Son olarak, pozitron-emisyon tomografisi (PET)'nin, tanıdaki standart görüntüleme yöntemleri arasındaki yerini halen alamadığ

\section{Biyopsi}

Son yıllarda aktif izlem (Aİ) ve ablatif tedavilerin (AT) yaygınlaşması nedeniyle tanı amaçlı perkütan böbrek biyopsisi sayıları artmaktadır (2).

Perkütan böbrek biyopsisi iki teknikle yapılmaktadır; kor iğne biyosisi (KİB) ve ince iğne aspirasyon biyopsisi (İ̇AB). KİB solid kitleler için tercih edilirken, KİB ve İIAB kombinasyonu kistik lezyonlar için (özellikle Bosniak tip 4) önerilmektedir (2). US eşliğinde ve BT kılavuzluğunda benzer tanısal doğruluk elde edilmektedir $(2,18)$. Alınacak parça sayısının biri santral ve diğeri kitle periferinden olmak üzere en az iki adet olması önerilmektedir $(2,18,19)$. Özellikle büyük kitlelerin merkezi bölgelerindeki nekrotik alanlar biyopsinin doğ- 
ruluk oranını düşürmektedir (2). Park SY ve ark.'ları renal kitlenin $2 \mathrm{~cm}$ ve altında oluşu ve kitle yerleşiminin üst polde olmasını başarısız biyopsi nedenleri olarak bildirmektedir (19). Tümör ekimini engellemek için bir koaksiyel kılavuz kılıf ya da kanül kullanılarak biyopsi yapılması önerilmekte$\operatorname{dir}(2)$.

Perkütan renal biyopsilerin tanısal başarısı solid tümörlerde \%78-97 arasındadır. Başarısız biyopsi durumunda tekrar biyopsi ya da cerrahi müdahale mutlaka düşünülmelidir $(2,18)$. Salem ve ark.'ları tekrar biyopsilerin tanısal başarı oranını \%66.7 olarak bildirmiştir (20).

Perkütan renal biyopsilerin yüksek duyarlılığına rağmen Fuhrman derecelendirmesinde yetersiz kalması, biyopsiye dayalı derecelendirmede Fuhrman yerine yüksek dereceli ve düşük dereceli olmak üzere iki kademeli değerlendirmenin yapılması tartışılmaktadır (2).

\section{Tedavi}

Histopatolojik çalışmalarda KBK'lerin \%20'sinin benign, $\% 55-60$ 'ının yavaş seyirli RHK olduğu ve geri kalanların da potansiyel olarak agresif davranışlı RHK'ler olduğu gösterilmiştir $(1,21)$. KBK'leri radikal nefrektomi $(R N)$ ve artan oranda da; nefron koruyucu cerrahi (PN) ile tedavi edilmektedirler. Son yıllarda laparoskopik ve robotik cerrahide artan deneyim ve sonuçlara paralel olarak bu teknikler açık cerrahiye göre daha çok tercih edilir hale gelmişlerdir (1). Ablatif tedaviler umut vericidir ancak uzun dönem takipli çalışmalar halen gereklidir (1). Cerrahi yerine Aİ tercihi ile ilişkili bilgilerimiz her geçen gün artmaktadır.

\section{Cerrahi mi, aktif izlem mi?}

Aİ, tümör çapının bir seri abdominal görüntüleme yöntemi (US, BT veya MR) ile takibi ve takip esnasında klinik büyüme gösteren tümörlerin cerrahi ile çıkarılmasını öngören bir protokol olarak tanımlanır (2). KBK'lar hakkında Aí ve gözlemin bir tedavi alternatifi olması tartışması devam etmektedir. Ana fikir, Aİ uygulanarak cerrahi ile benzer sonuçlar elde edilip edilemeyeceği temeli üzerine oturur. AI'in tercih edilme sebebi özellikle yaşlı hastalarda eşlik eden komorbiditelerin, yaşamı yavaş seyirli KBK'lardan daha fazla tehdit ettiği kanısıdır. Bu konuda prostat kanseri izlemindeki stratejiden esinlenilmiştir (1).

Son on yılda Aİ ile ilgili olarak birçok çalışma bulunmaktadır. Bu çalışmalarda birçok sayıda KBK'nin yavaş seyirli olduğu ve hastanın hayatını tehdit etmediği gösterilmiştir (1). Brunocilla ve ark.'ları toplam 60 adet kontrast tutan kitlesi olan 58 hastanın bilgilerini geriye yönelik olarak taramışlardır. Bu hasta grubundan 4 hastaya erken dönemde cerrahi tedavi yapilırken; 14 hastaya bir süre takip sonrası geciktirilmiş cerrahi uygulanmış, 40 hasta ise Aİ'e alınmıştır (22). Sonuçta bu hasta grubundan yalnızca 2'sinin metastatik hastalık nedeni ile öldüğü bildirilmiştir. Bu sonuçlarla yazarlar KBK'lerinin çoğunun yavaş seyirli olduğu ve düşük metastatik potansiyel gösterdiğini öne sürmüşlerdir. Ayrıca yazarlar, geciktirilmiş cerrahiye ihtiyaç duyanların uzamsal ve hacimsel olarak daha hızlı büyüme oranlarına sahip olduklarını ve bunun Aİ esnasında rahatlıkla tespit edilebileceğini belirtmişlerdir. Özetle Aİ, düşük yaşamsal beklentisi olan seçilmiş hastalar için uygun bir seçenek olabilir.

Ancak, Ȧ̇ adaylarını tespit etmek için bazı kriterler ortaya konulmalıdır. Bu konuda Jacobs ve ark.'ları KBK bulunan hastalarda tümör büyüklüğ̈̈, Charlson komorbidite indeksi (CKİ), Doğu Birleşik Onkoloji Grubu'nun performans durumu kriterleri (ECOG-PD) ve hesaplanmış glomerüler filtrasyon hızı (hGFR) gibi faktörlerin rolünü araştırmışlardır (23). İdeal kriterler olarak, tümör çapı $\leq 4 \mathrm{~cm}, \mathrm{CKI} \geq 2$, DBOG $\mathrm{PD} \geq 2$ ve hGFR $<60 \mathrm{ml} / \mathrm{dk}$ olarak belirtilmiştir. Sonuçta, tümör çap $<3 \mathrm{~cm}$, ECOG PD $\geq 2$ ve endofitik tümörün varlığı şeklinde tanımladıkları kombinasyonun; Aİ için en kestirimci metot olduğunu vurgulamışlardır. Audenet ve ark.'ları başka bir çalışmada CKİ $4^{\prime}$ ten büyük olan hastaların diğer hastalara kıyasla erken cerrahiye daha az uygun olduğunu iddia etmişlerdir (24). Diğer bir çalışmada ise; Abouassaly ve ark.'ları $\geq 60$ yaş hastalarda Aİ ile parsiyel nefrektomiyi yaşam beklentisi açısından değerlendirmişler ve parsiyel nefrektomi'nin Aİ'e göre ortalama 9.5 aylık yaşam avantajı sağladığını ortaya koymuşlardır (25).

Prostat kanseri tedavi protokolündekine benzer şekilde böbrek kitleleri için nomogramlar da üzerinde çalışılan konulardan biridir. Bu sistemler TNM veya Fuhrman derecelendirme sistemlerinden daha doğru sonuç verebilme potansiyeline sahiptirler (2). Koo KC ve ark.'ları Kutikov'un 2010 'da hazırladığı renal nefrometri skorunu (RNS) denemiş ve KBK'inde yüksek dereceli RHK'ların tespitinde güvenilir olmadığını belirtmişlerdir (26). Benzer şekilde, Bagrodia ve ark.'ları da RNS'nin malign ve benign lezyonları ayırt edemediğini bildirmişlerdir (27).

Aslında, cerrahi ile Aİ arasındaki çekişme yaşlı hasta grubundaki aşırı tedavi endişesine dayanır. Nefron koruyucu cerrahi, son 15 yıldaki birçok çalışmada ortaya konulduğu gibi güvenilir bir yöntemdir (2). Ayrıca günümüzde, $4 \mathrm{~cm}$ 'in altındaki kitleler için en iyi tedavi yöntemi olarak bildirilmektedir. Her hastaya PN yapılmasının aşırı bir tedavi doğuracağı kabul edilmelidir. Öyleyse Aİ aşırı tedavi ile yetersiz tedavi arasinda denge kurabilecek uygun bir yöntem olarak düşünülebilir. Yine de; yukarıda belirtildiği gibi bir KBK'nın ölümcül bir hastalığa ilerleyip ilerlemeyeceğini bildirecek yeterli radyolojik veya histopatolojik ilerleme ve bilgiye sahip değiliz. Ayrıca bazı KBK'lerinin daha başvuru anındaki mikrometastazlar ve konkomitan senkron metastazlar veya zaman içinde gelişecek metastazlar ya da çok kısa zamanda gelişen ani tümöral büyümeler nedeni ile klinik olarak önemli olduğunu biliyoruz. Bu kriterlerin hiçbiri tümör çapı veya yıllık büyüme oranı ile ilişkili değildir $(1,28,29)$.

Aİ esnasında müdahale zamanının belirlenmesi ve izlem prosedürleri henüz ürologların üzerinde anlaşmaya varabildikleri konular değildir. Hwang ve ark.'ları benign tümörlerin KBK arasında değerlendirilerek Aİ'e alınmasını, diğer taraftan da hızlı büyüyen tümörlerin küçük tümör hacmine de sahip olsalar KBK olarak değerlendirilmemeleri ve cerrahi ile tedavi edilmelerini önermişlerdir (1). Bu çalışmada büyüme oranı malign lezyonları ayırt etmede en kestirimci faktör olarak belirtilmiştir. Ancak hızlı büyüyen kitleleri tanımlamak adına üzerinde anlaşılmış bir yıllık büyüme oranı ortaya konmuş değildir.

Gerçekten de; 4 cm'den küçük kitlesi olan ve ek komorbiditeler, düşük yaşam beklentisi ve ileri yaş ( $\geq 75$ yaş gibi) gibi faktörler nedeni ile morbiditesi yüksek olarak nitelendirilen hastalar için başlangıçta Aİ mantıklı bir seçim olabilir $(1,30,31)$. Yine de; yukarıda belitrilen riskler nedeni ile Aİ halen daha EAU klinik rehberlerinde yüksek kanit düzeyine sahip bir terapötik öneri olarak yerini alamamıştır (2). 
Önümüzdeki yıllarda Aİ ile ilişkili bilgilerimizin artması ve belki bazı teknolojik gelişmeler konuyu aydınlatıcı ve umut verici olabilir. Aİ kararı bütün risk ve tedavi şekilleri tartışıldiktan sonra klinisyen ve hastanın birlikte vermesi gereken bir karardır.

\section{Hangi cerrahi teknik?}

Parsiyel nefrektomi (PN), T1a tümörler ve KBK için cerrahi tekniğine bakılmaksızın en iyi seçenektir. Laparoskopik ve daha yeni olan robotik parsiyel nefrektomi (LPN ve RPN) fonksiyonel ve onkolojik sonuçları açısından açık PN ile karşllaştırılabilir düzeydedir. Radikal nefrektomi (RN) ise hasta PN'ye uygun olmadığı takdirde uygulanmalıdır $(2,30)$.

Açık parsiyel nefrektomi (APN) ile açık radikal nefrektomi (ARN)'nin ve LPN ile LRN'nin onkolojik sonuçları karşılaştırılabilir düzeydedir (1). Bununla birlikte LPN'yi altın standart teknik olarak kabul edebilecek yeterli bilgi bulunmamaktadır (32). Tekniğine bakılmaksızın PN standart ameliyat olarak yerini korumaktadır. Ek olarak, Klinghoffer ve ark.'ları LPN'nin uygulanamadığı yetersiz teknik imkanı bulunan cerrahi birimlerde, PN'nin LRN'ye kiyasla maliyetetkinlik açısından daha üstün olduğunu göstermişlerdir (33). Diğer yandan Scosyrev ve ark.'ları EORTC 31904 çalışmasında ortaya çıan, PN'nin nefron koruyucu cerrahi olmasına rağmen $R N^{\prime}$ ye kıyasla genel sağ kalıma ciddi bir katkısının olmadığı şeklindeki sonucu okunmasını tavsiye ettiğimiz bir makalede tartışmışlar ve ve karşı böbreği normal olan hastalar için RN'nin geçerli bir tedavi yöntemi olduğunu savunmuşlardır (21). PN'de cerrahi sonrası renal fonksiyonlarda azalma bilinen bir problemdir.

Robotik teknoloji de giderek daha fazla oranda üroloji cerrahi pratiğinin içerisinde yer almaktadır (34). Krane ve ark.'ları robotik parsiyel nefrektomi (RPN)'nin T1b tümörler için bile oldukça başarılı bir yöntem olarak bildirmelerine karşın; Froghi ve ark.'ları T1a tümörler için LPN ve RPN arasında genel anlamda belirgin bir fark saptamamışlardır $(35,36)$. Benzer şekilde, Kane yaptığı çalışmada RPN'nin LPN ile benzer klinik sonuçlar veren ancak çok daha hızlı öğrenme eğrisi olan bir yöntem olduğunu belirtmişlerdir (37). Diğer taraftan, Kim ve ark.'ları PN'yi savunmakla beraber eğer operasyon öncesinde uzun iskemi zamanı öngörülüyorsa (örn: $>25 \mathrm{dk}$.) damar klempi yerine hipotermi tekniğinin kullanılmasını önermişlerdir (38). Son dönemde gündeme gelen tek port cerrahiyi Schips ve ark.'ları damar klempi kullanmadan denemişlerdir ve çalışmada yer alan 21 hastadan elde edilen veriler sonunda tek port cerrahinin uygulanabilir, güvenli ve bunlarla birlikte kozmetik açıdan tatmin edici olduğunu belirtmişlerdir. (39) Minimal invazif cerrahi konusundaki benzer sonuçlar Neri ve ark.'ları tarafından da konfirme edilmiştir (40).

\section{Ablatif tedaviler (AT)}

Cerrahi ile Aİ arasındaki denge henüz kurulmadığından minimal invazif yöntemler arasında adı geçen $\mathrm{AT}^{\prime}$ ler bu noktada faydalı olabilir. Ancak yetersiz kanıt düzeyleri nedeni ile tekniklerden hiçbirinin son EAU klinik rehberinde önerilmemiş olduğunu belirtmek yerinde olacaktır.

En çok bilinen AT yöntemleri bir görüntüleme yöntemi eşliğinde ya da laparoskopik direkt görüş altında uygulanan radyofrekans ablasyon ve kriyoablasyondur. Hiler ya da intraparankimal tümörler PN esnasında cerrahiyi zorlaştırabilir (41). Böyle olgularda, laproskopik ya da açı cerrahiye uygun olmayan hastalarda AT uygun bir seçim olabilir. Radyofrekans ablasyon seçeneklerden biridir $(42,43,44)$. Ancak yapilan bir metaanalizde radyofrekans ablasyondan ziyade kriyoablasyon daha ön planda önerilmektedir (45). Özellikle anteriorda kitlesi olan veya üretere ya da çevre organlara komşuluk gösteren kitlesi bulunan hastalarda laparoskopik kriyoablasyon cerrahiye alternatif bir tedavi yöntemi olarak önerilmektedir (46). Kriyoablasyon esnasında çevre organ hasarının oluşmaması için pnömodiseksiyon tekniğinin kullanılması faydalı olabilir (47).

Üzerlerinde araştırmaların devam ettiği diğer AT seçenekleri HIFU ablasyon ve elektrolizdir. Ancak bu yöntemler hakkındaki veriler yorum yapmak için yetersiz düzeydedir $(45,48)$.

\section{Sonuç}

KBK böbrek tümörleri içinde tedavi ve takip açısından üzerinde en çok tartışılan konulardan biri olmaya devam etmektedirler. Erken tanı ve uygun küratif tedavi ile başarı sağlanması, diğer yanda ise aşırı tedavi kavramının çakıştı̆̆ bir alan olması nedeniyle konuyu netleştirmek elimizdeki bilgiler 1şığında bugün tam olarak mümkün değildir. KBK'nin seyrinin daha iyi anlaşılması için daha fazla sayıda hasta içeren ve uzun süre takip süresi raporlayan yeni çalışmalar gereklidir.

\section{Kaynaklar}

1. Hwang EC, Yu HS, Kwon DD. Small renal masses: surgery or surveillance. Korean J Urol. 2013;54:283-8.

2. Ljungberg B, Bensalah K, Bex A, Canfield S, Dabestani S, Hofmann F, et al. Guidelines on Renal Cell Carcinoma. EAU Guidelines. Update March 2013.

3. Zhu Y, Wang HK, Zhang HL, Yao XD, Zhang SL, Dai B, et al. Visceral obesity and risk of high grade disease in clinical t1a renal cell carcinoma. J Urol. 2013;189:447-53.

4. Kim SP, Alt AL, Weight CJ, et al. Independent validation of the 2010 American Joint Committee on Cancer TNM classification for renal cell carcinoma: results from a large, single institution cohort. J Urol 2011;185:2035-9.

5. Novara G, Ficarra V, Antonelli A, et al; SATURN ProjectLUNA Foundation. Validation of the 2009 TNM version in a large multi-institutional cohort of patients treated for renal cell carcinoma: are further improvements needed? Eur Urol 2010;58:588-95.

6. Kunkle DA, Egleston BL, Uzzo RG. Excise, ablate or observe: the small renal mass dilemma: a meta-analysis and review. J Urol 2008;179:1227-33.

7. Duchene DA, Lotan Y, Cadeddu JA, Sagalowsky AI, Koeneman KS. Histopathology of surgically managed renal tumors: analysis of a contemporary series. Urology 2003;62:827-30.

8. Ramirez ML, Evans CP. Current management of small renal masses. Can J Urol 2007;14 Suppl 1:39-47.

9. Patard JJ, Rodriguez A, Rioux-Leclercq N, et al. Prognostic significance of the mode of detection in renal tumours. BJU Int 2002;90:358-63.

10. Kato M, Suzuki T, Suzuki Y, et al. Natural history of small renal cell carcinoma: evaluation of growth rate, histological grade, cell proliferation and apoptosis. J Urol 2004;172:863-6. 
11. Tsui KH, Shvarts O, Smith RB, et al. Renal cell carcinoma: prognostic significance of incidentally detected tumors. J Urol 2000;163:426-30.

12. Jamis-Dow CA, Choyke PL, Jennings SB, Linehan WM, Thakore KN, Walther MM. Small renal masses: detection with CT versus US and pathologic correlation. Radiology. 1996;198:785-8.

13. Kim KH, Yun BH, Jung SI, Hwang IS, Hwang EC, Kang $\mathrm{TW}$, et al. Usefulness of the ice-cream cone pattern in computed tomography for prediction of angiomyolipoma in patients with a small renal mass. Korean J Urol. 2013;54:504-9.

14. Meng MV. Commentary on "Predicting the histology of small renal masses using preoperative dynamic contrastenhanced magnetic resonance imaging." Kim JH, Bae JH, Lee KW, Kim ME, Park SJ, Park JY. Department of Urology, Soonchunhyang University Hospital, Seoul, Korea. Urol Oncol. 2013;31:133-4.

15. Pierorazio PM, Hyams ES, Tsai S, Feng Z, Trock BJ, Mullins JK, et al. Multiphasic enhancement patterns of small renal masses on preoperative computed tomography: utility for distinguishing subtypes of renal cell carcinoma, angiomyolipoma, and oncocytoma. Urology. 2013;81:1265-71.

16. Bird VG, Kanagarajah P, Morillo G, Caruso DJ, Ayyathurai R, Leveillee R, et al. Response by authors re: Differentiation of oncocytoma and renal cell carcinoma in small renal masses : the role of 4-phase computerized tomography. World J Urol. 2013;31:1011-2.

17. Payton S. Small renal masses: Indocyanine green cannot predict malignancy. Nat Rev Urol. 2013;10:250.

18. Tsivian M, Rampersaud EN Jr, Laguna Pes MD, Joniau S, Leveillee RJ, Shingleton WB, et al. Small renal mass biopsy - how, what and when: report from an international consensus panel. BJU Int. 2013;14.

19. Park SY, Park BK, Kim CK, Kwon GY. Ultrasound-guided core biopsy of small renal masses: diagnostic rate and limitations. J Vasc Interv Radiol. 2013;24:90-6.

20. Salem S, Ponsky LE, Abouassaly R, Cherullo EE, Isariyawongse JP, Maclennan GT, et al. Image-guided biopsy of small renal masses in the era of ablative therapies. Int J Urol. 2013;20:580-4.

21. Scosyrev E, Messing E, Campbell S. Radical versus partial nephrectomy for a small renal mass: does saving nephrons save lives? Expert Rev Anticancer Ther. 2013;13:1349-51.

22. Brunocilla E, Borghesi M, Monti C, Schiavina R, Martorana G. Surveillance for small renal masses: retrospective analysis of a cohort of 42 patients with long-term followup. Int Urol Nephrol. 2013;45:307-12.

23. Jacobs BL, Tan HJ, Montgomery JS, Weizer AZ, Wood DP, Miller DC, et al. Understanding criteria for surveillance of patients with a small renal mass. Urology 2012;79:102732.

24. Audenet F, Audouin M, Drouin SJ, Comperat E, Mozer P, Chartier-Kastler E, et al. Charlson score as a single pertinent criterion to select candidates for active surveillance among patients with small renal masses. World J Urol. 2013 Jul 20.

25. Abouassaly R, Yang S, Finelli A, Kulkarni GS, Alibhai $\mathrm{SM}$. What is the best treatment strategy for incidentally detected small renal masses? A decision analysis. BJU Int 2011;108:E223-31.
26. Koo KC, Yoo H, Shin TY, Kim J, Choi YD, Rha KH, et al. External validation of the RENAL nephrometry score nomogram for predicting high-grade renal cell carcinoma in solid, enhancing, and small renal masses. World J Urol. 2014;32(1):249-55.

27. Bagrodia A, Harrow B, Liu ZW, Olweny EO, Faddegon $S$, Yin G, et al. Evaluation of anatomic and morphologic nomogram to predict malignant and high-grade disease in a cohort of patients with small renal masses. Urol Oncol. 2014;32:37.e17-23.

28. Jewett MA, Mattar K, Basiuk J, Morash CG, Pautler SE, Siemens DR, et al. Active surveillance of small renal masses: progression patterns of early stage kidney cancer. Eur Urol 2011;60:39-44.

29. Alasker A, Williams SK, Ghavamian R. Small renal mass: to treat or not to treat. Curr Urol Rep. 2013;14:13-8.

30. Payton S. Small renal masses: Support for active surveillance in patients aged $\geq 75$ years. Nat Rev Urol. 2013;10:253.

31. Power NE, Silberstein JL, Touijer K.Is laparoscopic partial nephrectomy already the gold standard for small renal masses? Arch Esp Urol. 2013;66:90-8.

32. Klinghoffer Z, Tarride JE, Novara G, Ficarra V, Kapoor A, Shayegan B, et al. Cost-utility analysis of radical nephrectomy versus partial nephrectomy in the management of small renal masses: Adjusting for the burden of ensuing chronic kidney disease. Can Urol Assoc J. 2013;7:108-13.

33. Hillyer SP, Bhayani SB, Allaf ME, Rogers CG, Stifelman $\mathrm{MD}$, Tanagho $\mathrm{Y}$, et al.Robotic partial nephrectomy for solitary kidney: a multi-institutional analysis.Urology. 2013;81:93-7.

34. Krane LS, Hemal AK. Robotic and laparoscopic partial nephrectomy for T1b tumors. Curr Opin Urol. 2013;23:41822.

35. Froghi S, Ahmed K, Khan MS, Dasgupta P, Challacombe B. Evaluation of robotic and laparoscopic partial nephrectomy for small renal tumours. BJU Int. 2013;112:E322-33.

36. Kane C. Commentary on "a matched comparison of perioperative outcomes of a single laparoscopic surgeon versus a multisurgeon robot-assisted cohort for partial nephrectomy." Ellison JS, Montgomery JS, Wolf Jr JS, Hafez KS, Miller DC, Weizer AZ, Department of Urology, University of Michigan, Ann Arbor, MI, USA: J Urol 2012;188:45-50. Urol Oncol. 2013;31:275.

37. Kim SP, Thompson RH. Kidney function after partial nephrectomy: current thinking. Curr Opin Urol. 2013;23:105-11.

38. Schips L, Berardinelli F, Neri F, Tamburro FR, Cindolo L. Laparoendoscopic single-site partial nephrectomy without ischemia for very small, exophytic renal masses: surgical details and functional outcomes. Eur Urol. 2013;63:759-65.

39. Neri F, Berardinelli F, Cindolo L, Sountoulides P, Pellegrini F, Mirone V, et al. Is a Single-Site Laparoendoscopic Approach a Real Surgical Advancement for the Management of Small Renal Masses? Surg Technol Int. 2013 Sep 30;XXIII.

40. Ceccarelli G, Codacci-Pisanelli M, Patriti A, Ceribelli C, Biancafarina A, Casciola L. Robotic-assisted transperitoneal nephron-sparing surgery for small renal 
masses with associated surgical procedures: surgical technique and preliminary experience. Updates Surg. 2013;65:183-90.

41. Gallego Vilar D, Cifrian García M, García Fadrique G, García Vila J, Gallego Gómez J. Laparoscopic radiofrequency for small renal masses. What is the best imaging technique? Arch Esp Urol. 2013 Jan-;66:60-70.

42. Estébanez J, Gutiérrez MA, Linazasoro I, Belloso I, Cano C, Sanz JP. Treatment of small renal masses with laparoscopic radiofrequency ablation. Arch Esp Urol. 2013;66:54-9.

43. Leveillee RJ, Castle SM, Gorbatiy V, Salas N, Narayanan G, Morillo-Burgos G, et al. Oncologic outcomes using real-time peripheral thermometry-guided radiofrequency ablation of small renal masses. J Endourol. 2013;27:480-9.

44. Klingler C, Margreiter M, Marberger M. New ablative treatments for small renal masses: HIFU ablation. Arch Esp Urol. 2013;66:79-89.

45. Cordeiro ER, Barwari K, Anastasiadis A, García M, Branco F, de la Rosette JJ, et al. Laparoscopic cryotherapy for small renal masses: Current State. Arch Esp Urol. 2013;66:41-53.

46. Maurice MJ, Haaga JR, Nakamoto DA, Ponsky LE. Pneumodissection: an alternative protective technique for the percutaneous cryoablation of small renal masses. Urol Int. 2013;90:381-3.

47. Lloyd M, Miller J, Moretti KL, Texler M, Maddern GJ. Electrolysis - a new method of renal ablation? BJU Int. 2012;110 Suppl 4:77-9.

48. Patel SR, Abel EJ, Hedican SP, Nakada SY. Ablation of small renal masses: practice patterns at academic institutions in the United States. J Endourol. 2013;27:15861.

Yazışma Adresi

Mustafa Sofikerim,

Acıbadem Kayseri Hastanesi, Üroloji Kliniği,

Melikgazi, Kayseri

Tel: +90 3522073917

e-mail: mustafa.sofikerim@acibadem.com.tr 